\title{
DESIGN AND MODELLING OF A LIGHT DUTY TRENCHER FOR LOCAL CONDITIONS
}

\author{
Delesa Kajela', Hirpa G. Lemu² \\ 1 School of Mechanical Engineering, Jimma University, 378 Jimma, Ethiopia, e-mail: delkej@gmail.com \\ 2 Faculty of Science and Technology, University of Stavanger, N-4036 Stavanger, Norway, e-mail: Hirpa.g.lemu \\ @uis.no
}

Received: 2018.01.15 Accepted: 2018.02.01 Published: 2018.03.01

\begin{abstract}
The adverse effect of using traditional equipment particularly in developing countries is that it is time and energy consuming, less productive, difficult and more manpower is required. Hence, it is necessary to design and produce low price, and simple machines that can narrow this gap. The objective of the project reported in this article is to design and model a light duty trencher that is used for trenching the ground or soil for making ditch, and used for agricultural, ground cabling, ground piping and drainage system. The designed machine trenches, maximum of $1 \mathrm{~m}$ depth, $30 \mathrm{~cm}$ width and has adjustable length. The working mechanism is fully hydraulic, and equipped with an engine of $12.7 \mathrm{hp}$, which provides suitable power for the pump that delivers $23 \mathrm{l} / \mathrm{min}$ at $1500 \mathrm{rpm}$ to drive hydraulic motors and actuators.
\end{abstract}

Key words: Trencher, ditch, fundamental earth-moving equation (FEE), Evans's theory, trenching tooth, stress Analysis.

\section{INTRODUCTION}

Trenchers have been traditionally used as construction equipment to dig trenches, especially for laying pipes or cables, installing drainage, irrigation, installing fencing, and in preparation for trench warfare [16]. The common application areas of trenching include:

1. Water drainage in rectangular ditch,

2. Irrigation,

3. Underground pipes installation,

4. Erosion protection and

5. Underground cable installations.

Studies show that the key factors that led to deep-rooted changes in the industrial system of the Western World are the introduced technological and institutional models such as the Fordist mass production principle $[17,18]$ and utilization of the right tools and equipment in the mass production process. In many developing countries such as Ethiopia, however, there is a gap between the development of technology and the utilization of modern equipment in every sector. Unlike the developed countries, the tools in use are still pickaxe, shovel and some are using micro excavators. For example, in the case of trenchers, there are different modern types, but most of the recent developed ones are still not introduced to our country, mainly due to cost, complexity of involved mechanisms that require well trained operator. Hence, in order to narrow the gap, it is necessary to design and produce low cost and simpler machines to operate, for instance that can minimize use of human labor and/or can be used with less training effort.

In order to define the design parameters, study of the worst-case work conditions where the trencher is used is necessary $[2,11,19]$. In other words, it is important to account for the mechanical behavior of the soil mass, which may exist in dry, bulk (with water content) and rock 
mixture and devise optimum geometry for imperfect trench installations $[12,15]$. This is because the performance in terms of the excavation rate and the wear and breakage of the bits depend on the mechanical property of the rock.

The performance of a trencher $[5,6]$ is expressed by its production (excavation) rate and by the bit consumption (due to wear and breakage). The production rate, i.e., the volume of material excavated per hour, affects the time necessary to excavate a trench. The bit-consumption rate, i.e., the number of bits which need to be replaced per cubic meter of rock material excavated, affects the equipment costs and the down-time necessary to replace the bits. Both the production rate and the bit-consumption rate determine the cost of an excavation.

The study reported in this article is, thus, intended to design and model a light duty trencher that is used for trenching the ground or soil for making ditch, and used for agricultural, ground cabling, ground piping and drainage system. Specifically, the work is aimed to

- reduce time and energy needed to trench,

- replace old and traditional trenching with the modern trenching machine,

- reduce manpower requirement for trenching,

- design a simple and efficient machine,

- optimize the design of digging parts such as teeth, cutting chain, arm, boom and crumber, main shaft, auger and sprocket.

The study involved calculations and analyses to determine the proper dimensions of its components and developing the models in a $3 \mathrm{D} \mathrm{CAD}$ system.

Following this introduction section, the article is organized as follows. First, a brief background technologies of trenchers are presented and followed by a design and modelling approach implemented to solve the problem. This section discusses the details of the used design concept, the design parameters and the force calculations (analyses) done on each key component. Finaly the key conclusions are presented.

\section{BRIEF BACKGROUNDS}

Though it is not simple to know the early history of trenching machines and find out exactly where and when it had been invented, reports [4] indicate that trenchers trencher drain machines were first mechanized in the US around 1920s and the trenching technology was introduced in Europe in 1950s. From this period the technology showed rapid developments worldwide. Trenchers may range in size from walk-behind models to attachments for a skid loader or tractor, to very heavy tracked heavy equipment. The most common types of trencher are wheel trencher, chain trencher, micro trencher and portable trencher. In more recent times, the cost-effectiveness and flexibility of trenching has become an important factor for saving energy and manpower.

Existing excavation trenchers have a number of limitations including:

- Rock trenchers are huge trucks, not light duty and expensive.

- Specific applications: Most of them are not suitable for all type of soil such as wet soil, hard soil and hard clay, which need different types of teeth. It means that they are designed only for single purpose and for example they can't operate for both soil and rocks.

- Portable trencher machines don't have a seat and stand on plate for the operator and the operator will get tired after long operation hour. They are also installed for specified width and it is difficult to increase the width when needed. Once they passed first round trenching, they are not capable for second round trenching to increase the ditch width.

- Some models use trenching types with less digging depth, for instance E-Z Trench 9100 uses rotary disk while Kwik-Trench KT2400B uses triple $\mathrm{V}$ belt.

- The hydraulic versions are not fully hydraulic, as a result, they have many components and parts to operate and that will increase the cost.

- Difficulty of controlling: the operator has to walk behind the machine, holding the trencher and controlling the system operation for digging at the same time. At least the operator should have a seat or a stable stand.

- Most trenchers are difficult for operation and require certified operators. It is not simple to operate and understand the system.

Thus, new designs of trencher machines should address these and similar limitations of current designs. In the design discussed in this article, most of the above-listed limitations are taken into account. For instance, it has been possible to increase the width of the trench twice on the second round and it is easy to operate because anyone can easily understand the system. 


\section{DESIGN AND MODELING}

\section{Design Parameters}

The specifications or the parameters used in this project are not exactly the same as the experimental data for soil and rock properties of previous studies $[2,11,19]$. For the design purpose, additional data was taken to make this design applicable for general soil and rock conditions. So, the soil surcharge is the constant parameter and is considered as a standards value [20]. These data are taken from the soil parameter technical specification of CWS industries [CWS Web], which are based on laboratory experiments for various soil conditions. Among these, the soil density and soil cohesion are selected for the worst-case condition of soil as a hard clay $[1,3,14]$.

The parameters considered for this design include:

- 8 working hours per day,

- Earth Gravity $(g): 9.81 \mathrm{~m} / \mathrm{s}^{2}$

- Soil surcharge $(q): 10 \mathrm{~N} / \mathrm{m}^{2}$

- Soil density $(\gamma): 28000 \mathrm{~N} / \mathrm{m}^{3}$

- Soil cohesion (c): $25000 \mathrm{~N} / \mathrm{m}^{2}$

- Tensile strength of rock $\left(\sigma_{t}\right): 10 \mathrm{MPa}$

- Uniaxial compressive strength of rock $\left(\sigma_{c}\right)$ : $120 \mathrm{MPa}$

\section{The Design Concepts and the Design Process}

The design concepts were generated to meet the problem statement of the project. The process of generating design concepts consisted of investigating and testing of similar existing designs and developing a new design with an emphasis on simplicity of design, constructability and performance, while minimizing the overall weight.

The design process involved breaking down of the trencher machine system into subsystems as depicted in Fig. 1 and identifying machine components under each subsystem.

The design is based on a prime power provided by an engine that drives the hydraulic motors and actuators. The calculation of the power requirement to provide an outlet flow of pump of $23 \mathrm{l} / \mathrm{min}$ indicated that an engine of $8.7 \mathrm{~kW}$ or $11.7 \mathrm{hp}$ is required.

Thus, Honda GX340; 12.7 hp [10] has been selected because this engine can provide suitable power for the system.

While the hydraulic motors provide suitable power for the digging chain and drive wheels, the hydraulic actuators provide suitable power for the steering system, as well as to tilt the boom for digging angle. Some details of the working principles and actuator components are depicted in Fig. 2.

\section{CAD Modelling and Force Analysis}

Autodesk Inventor is used for the CAD modelling work and stress analysis. Depending on the type of trenching medium (condition), three types of cutters were designed:

1. Shark tooth for hard clay and dry soil (Fig. 3a)

2. Rock buster tooth (point-attack picks) for solid rock (Fig. 3b)

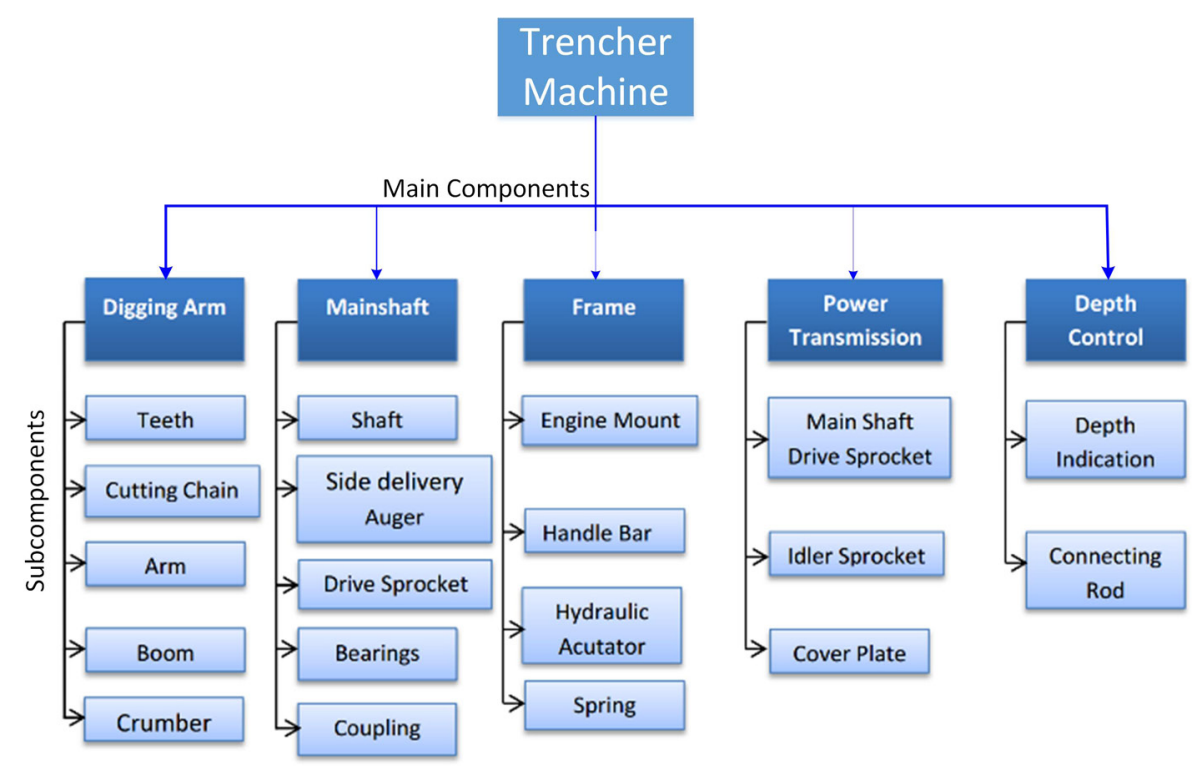

Fig. 1. Design process 
a)

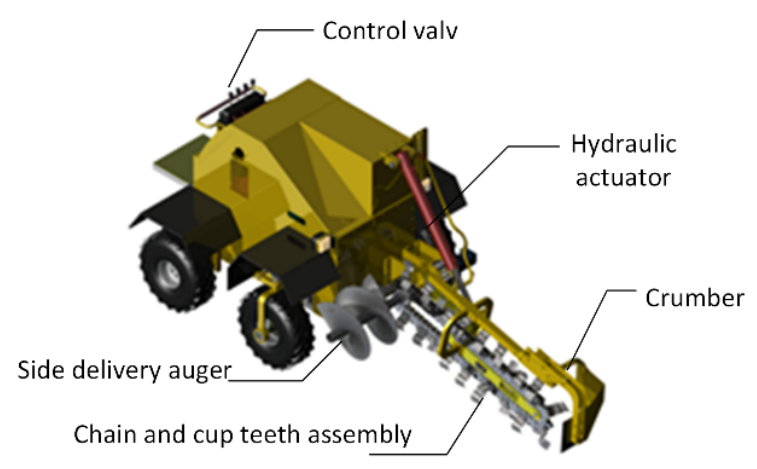

b)

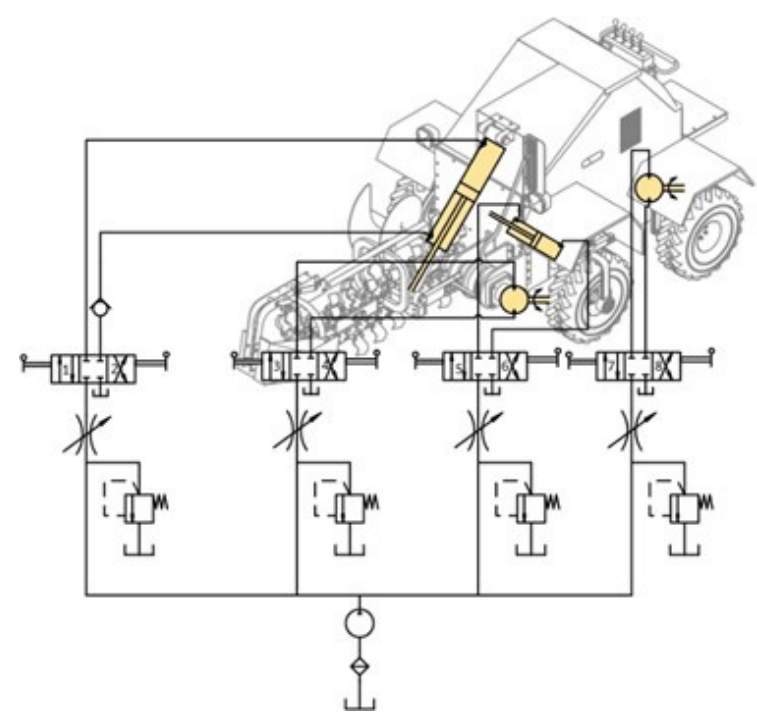

Fig. 2. Working principle

3. Cup tooth for clay, loamy ground, wet soil and any type of dirt soil can also use in combination with the other types to bring the soil or rock out of the hole. (Fig. 3c)

For a systematic study of trenching control of the soil, tool interaction forces are needed for stress analysis. The classical soil-tool model called the "Fundamental Earthmoving Equation (FEE)" along with a reformulated version is utilized for this application. This well-known FEE is described by Reece as $[3,16]$ :

$$
F_{s}=\left(\gamma d^{2} N_{\gamma}+c d N_{c}+q d N_{q}\right) w
$$

where $F S$ is the resistive force experienced at a blade, $\gamma$ is the soil density, $g$ is the gravity, $d$ is the tool depth below the soil, $c$ is the soil cohesion,

$q$ is the surcharge pressure acting on the soil surface, $w$ is the tool width and $N_{\gamma}, N C$ and $N q$ are dimensionless factors which depend not only on the soil frictional strength but also on the tool geometry and soil-tool strength properties.

The dimen sionless factors of Reece's equation are expressed as $[3,16]$ :

$$
\begin{aligned}
& N_{\nu}=\frac{\cot \rho+\cot \beta}{2[\cos (\rho+\delta)+\sin (\rho+\delta) \cdot \cot (\beta+\emptyset)]} \\
& N_{c}=\frac{1+\cot \beta \cdot \cot (\beta+\emptyset)}{[\cos (\rho+\delta)+\sin (\rho+\delta) \cdot \cot (\beta+\emptyset)]}
\end{aligned}
$$

$$
N_{q}=\frac{\cot \rho+\cot \beta}{[\cos (\rho+\delta)+\sin (\rho+\delta) \cdot \cot (\beta+\varnothing)]}
$$

If we assume a static equilibrium and that the shape of the failure surface can be approximated by a plane of unit width, the swept volume of soil displaced by the blade, at any moment, is assumed to account for the entire gravitational force acting on the blade. Therefore, the gravitational force $\left(\mathrm{F}_{\mathrm{g}}\right)$ is given by

$$
F_{g}=V_{s} \cdot \gamma
$$

where: $V_{s}$ is the swept volume and $\gamma$ is the soil density in $\mathrm{N} / \mathrm{m}^{3}$.

The swept volume (Vs) of the cup teeth is calculated as:

$$
V s=\text { w.d.l }=3.44 \times 10^{-4} \mathrm{~m}^{3}
$$

where: $w$ (tool width $)=0.04 \mathrm{~m}$; $d$ (tool depth) $=0.1 \mathrm{~m}$ and $I$ (length) $=0.086 \mathrm{~m}$.

The FEE assumes that the soil profile is horizontal and the assumptions for this 2D model are:

- Inertial forces are negligible.

- Surcharge is uniformly distributed on the tooth.

- Two forces are acting on soil tool interaction for flat soil surface, i.e. (1) shear force due to cutting and (2) gravitational force (for the cup teeth that draw out soil).

The static equilibrium analysis using an approximation of the failure surface of shark tooth 


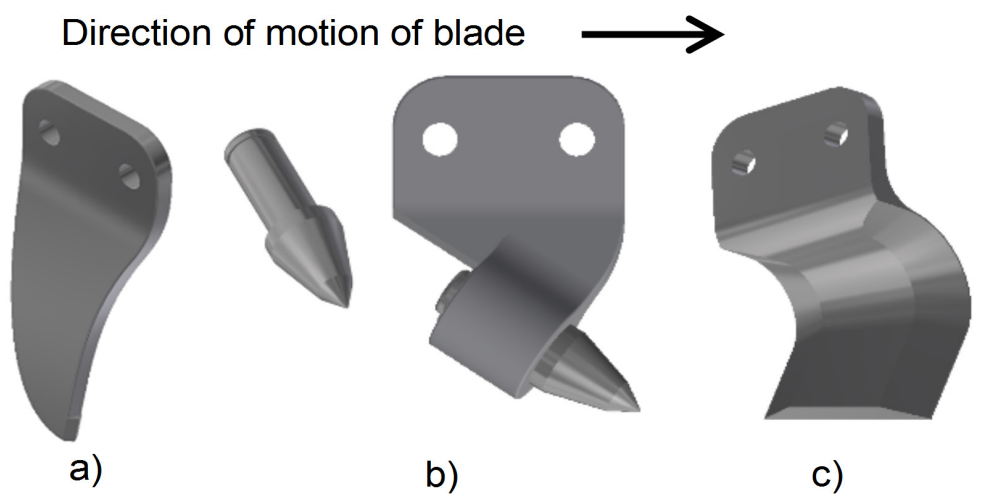

Fig. 3. Types of trenching tooth

is shown in Fig. 4, where $\mathrm{f}$ is the angle of soil-soil friction, $\mathrm{m}$ is the friction between the metal and the blade, $R$ is the force resisting movement of the wedge and $F$ is the total resistive force. All angles are selected for the condition of maximum resistive forces.

To move the cut soil in the case of cup tooth, gravitational force $\left(\mathrm{F}_{\mathrm{g}}\right)$ should be calculated, while to get the total force $\left(\mathrm{F}_{\mathrm{T}}\right)$, gravitational force should be added to resistive force $\left(\mathrm{F}_{\mathrm{s}}\right)$ as,

$$
F_{T}=F_{g}+F_{s}
$$

and calculations provide $\mathrm{F}_{\mathrm{T}}=196.842 \mathrm{~N}$ (for one cutting tooth).

As shown in Fig. 5, the boundary conditions for the stress analysis of the shark tooth and the cup tooth are defined at the bolted connections and the force directions are assumed as realistic as possible. As depicted, the average stress level (von Mises) is found significantly low.

To be able to predict the cutting force at pointattack picks (cutting geometry shown in Fig. 6), Evans's theory for point-attack picks is mostly used to estimate the peak cutting force for a given rock, i.e. when direct measurement of the cutting force is not available. His theory is based on the assumption that the penetrations of a conical pick attacking a buttock of rock $[7,8]$. This prediction formula is expressed as

$$
F_{C}=\frac{16 \cdot \pi \cdot \sigma_{t}^{2} \cdot d^{2}}{\sigma_{c} \cdot \cos ^{2} \theta}
$$

where $F_{C}$ is peak cutting force,

$\sigma_{t}$ is tensile strength of rock, $\mathrm{d}$ is cutting depth,

$\sigma_{c}$ is uniaxial compressive strength of rock and

$\theta$ is semi-angle of conical pick (degree).

With respect to practical conditions, some deficiencies (shortcomings) are observed in Eq. (7), which are:

- The cutting force (FC) does not reduce to zero when $\theta=0^{\circ}$, although it should, and

- The cutting force is inversely proportional to the compressive strength of rock, which is not the case in practice.

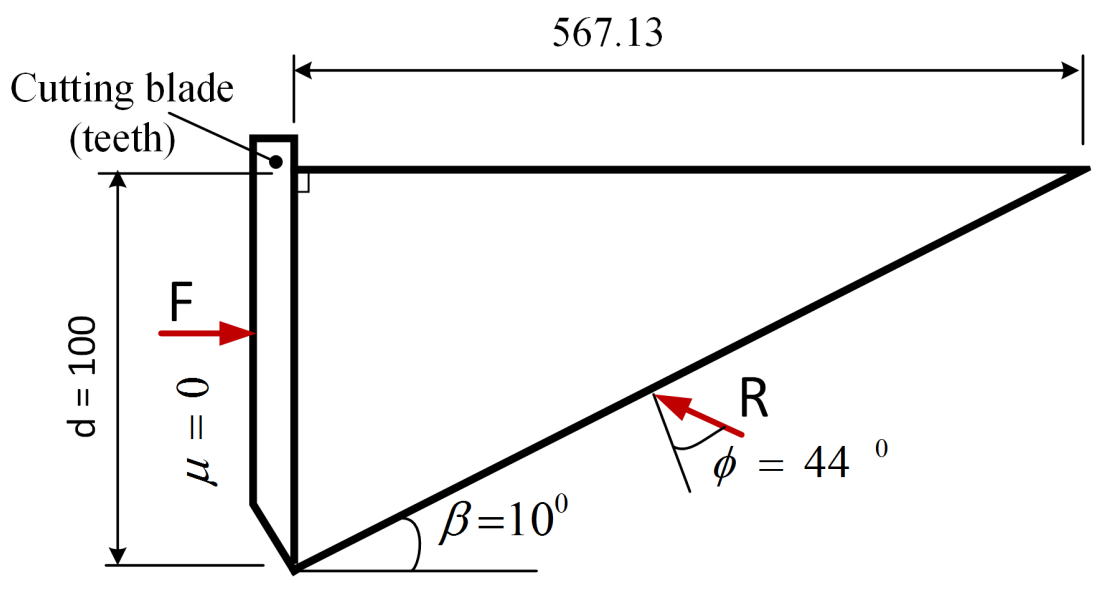

Fig. 4. Static equilibrium analysis of soil 
a)

Type: Von Mises Stress Unit: $\mathrm{MPa}$ $6 / 13 / 2015,1: 34: 28$ AM
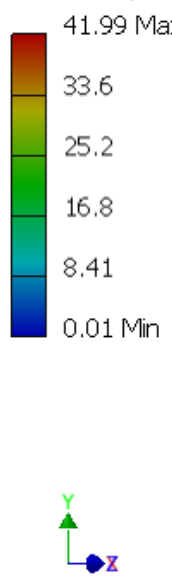

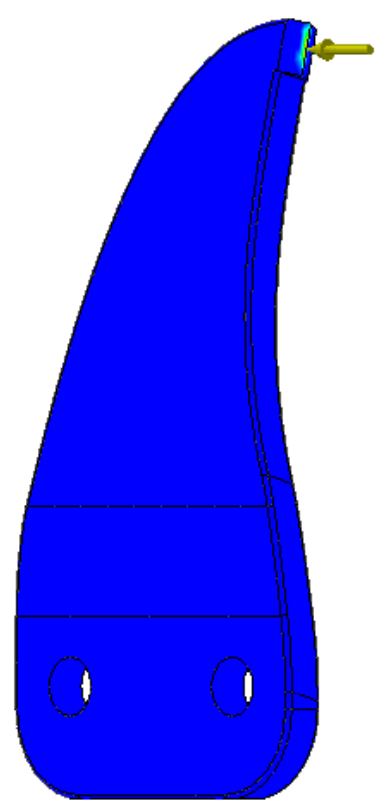

b)

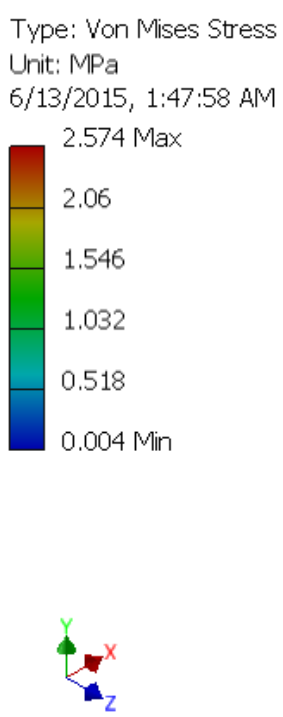

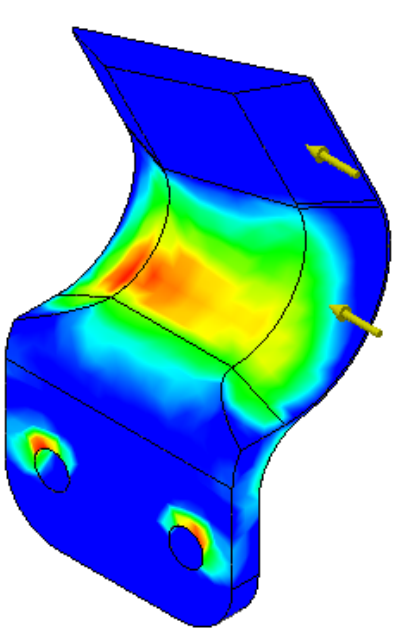

Fig. 5. Stress analysis report of shark tooth (L) \& cup tooth (R)

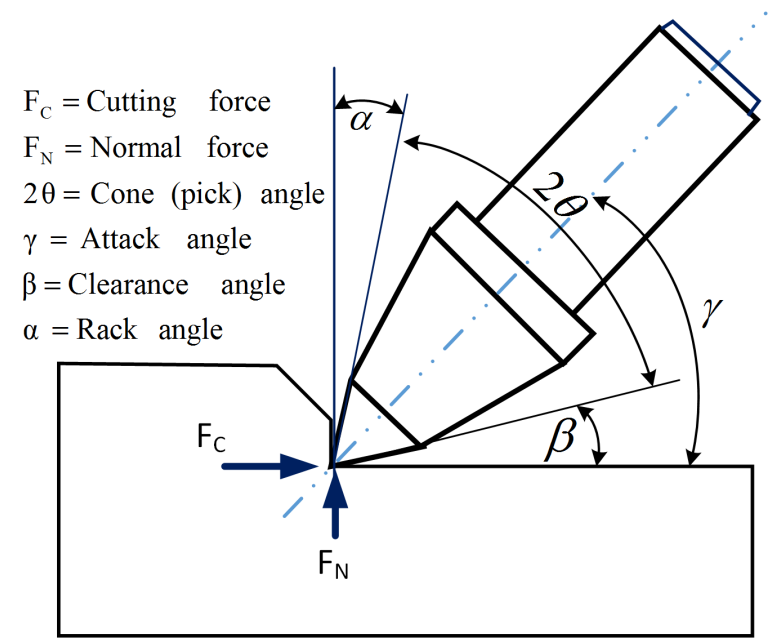

Fig. 6. Cutting geometry of rock buster (point-attack picks)

Maintaining the general features of the original theory, these two shortcomings of Evans's theory were eliminated in a recent study by Gok$\tan [9]$ where a modified prediction equation was proposed:

$$
F_{C}=\frac{4 \cdot \pi \cdot \sigma_{t} \cdot d^{2} \cdot \sin ^{2}(\theta+\psi)}{\cos (\theta+\psi)}
$$

where the parameters $\mathrm{F}_{\mathrm{C}}, \sigma_{\mathrm{t}}, \mathrm{d}$, and $\theta$ are as defined earlier in Eq. (7), and $\psi$ is the friction angle between the pick and rock (degrees).

The values for Eqs (7) and (8) are as follows [1,3]: - $\sigma_{\mathrm{t}}=10 \mathrm{MPa}$,
- $\sigma=120 \mathrm{MPa}$,

- $\mathrm{d}=10 \mathrm{~mm}(0.01 \mathrm{~m})$,

- $\psi=10^{\circ}$ and

- $\theta=32^{\circ}$.

Point attack tooth needs high cutting force than the others. For the next step, cutting force of point attack tooth is taken as the maximum, hence, $F_{C \max }$ is $7.571 \mathrm{kN}$. For design of chain for light duty operation [13], pitch $(p)$ is $50.8 \mathrm{~mm}$, diameter of the chain roller $\left(d_{1}\right)$ is $28.58 \mathrm{~mm}$, number of teeth on the sprocket $(t)$ is 10 and rotational speed of sprockets $(N)$ is $600 \mathrm{rpm}$. Furthermore, the number of chain links $(K)$ is 70 and the length of the chain $(L)$ is $3.556 \mathrm{~m}$. Further analysis of machine elements like sprocket, shaft, tapper and needle roller bearing, flexible coupling, spring, pin, keys and bolts were carefully done.

Design and analysis of crumber: For each design and analysis other components of the trencher such as crumber shoe, crumber side end support, side delivery auger, proper boundary conditions were defined and the estimated forces were applied.

The forces applied on crumber are, for instance, calculated for crumber shoe $(167.67 \mathrm{~N})$, crumber side end $(924.467 \mathrm{~N})$ and gravitational force. For the analysis model, the material properties of Steel AISI 1050 (yield strength of 206.84 $\mathrm{MPa}$ ) is used. The physical properties and analysis results of this component are shown in Table 1 and the stress plot is depicted in Fig. 8. As shown 


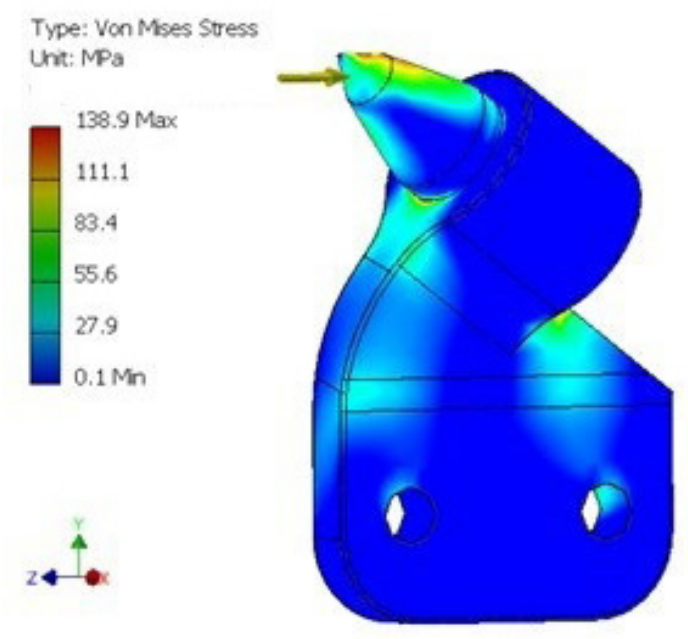

Fig. 7. Stress analysis report of rock buster tooth

Table 1. Physical properties and simulation summary

\begin{tabular}{|l|l|l|}
\hline Name & Minimum & Maximum \\
\hline Volume & $10093400 \mathrm{~mm}^{3}$ & \\
\hline Mass & $76.0601 \mathrm{~kg}$ \\
\hline Center of Gravity & $\begin{array}{l}\mathrm{x}=-548.03 \mathrm{~mm} \\
\mathrm{y}=286.79 \mathrm{~mm} \\
\mathrm{z}=51.017 \mathrm{~mm}\end{array}$ \\
\hline Von Mises Stress & $0.0035 \mathrm{MPa}$ & $70.223 \mathrm{MPa}$ \\
\hline 1st Principal Stress & $-12.975 \mathrm{MPa}$ & $78.436 \mathrm{MPa}$ \\
\hline 3rd Principal Stress & $-52.739 \mathrm{MPa}$ & $15.127 \mathrm{MPa}$ \\
\hline Displacement & $0 \mathrm{~mm}$ & $4.2778 \mathrm{~mm}$ \\
\hline Safety Factor & $3.45 \mathrm{ul}$ & $15 \mathrm{ul}$ \\
\hline
\end{tabular}

in the plot, the maximum average stress (von Mises) is about $70 \mathrm{MPa}$, which provides a safety factor against yielding of higher than 3 .

Design and analysis of boom: For this design, the same material as above is assumed and the forces acting on it are calculated. The applied force consisted of weight of crumber $(749.838 \mathrm{~N})$, weight of chain and teeth $(791.294 \mathrm{~N})$, gravitational force, tension in the chain due to sagging, force on crumber shoe and force on crumber side end. The analysis (Fig. 9) shows a maximum average stress of about $30 \mathrm{MPa}$ appearing at the boom, which is significantly low with respect to the material's yield strength.

Design and analysis of frame: The following force components were considered for the design and analysis of the frame:

- Weight of the frame connection structural steel.

- Force on connector for frame and hydraulics actuator due to mass of boom assembly $(67.25 \mathrm{~kg})$,

- Crumber assembly (76.44 kg),

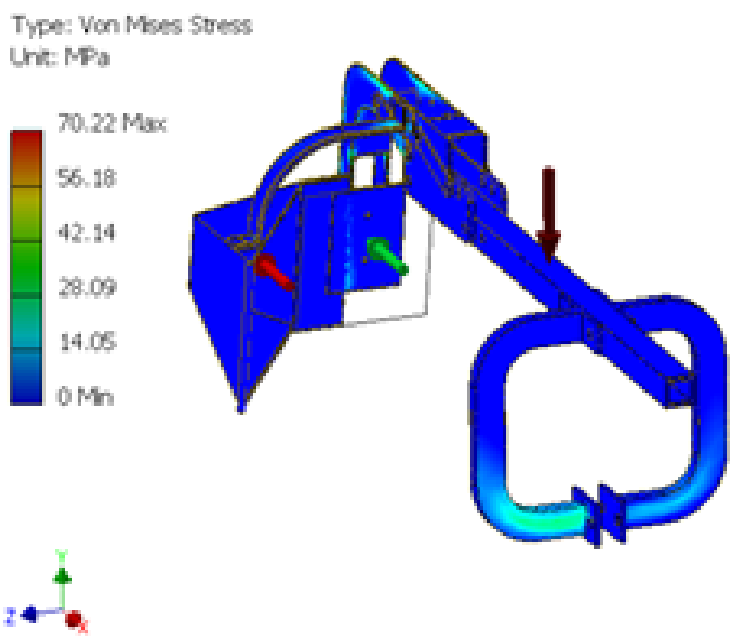

Fig. 8. Stress analysis report of crumber

- Chain assembly with cutting teethes $(80.66 \mathrm{~kg})$.

- Average weight of the operator and average weight of components inside the frame and

- Gravitational force.

The stress analysis was conducted upon accounting for all the above forces, and as depicted in Fig. 10, the stress level in the frame is extremely low.

Steering actuator: The hydraulic circuit of the system is shown in Fig. 11. When the four-way valve is actuated into the $5^{\text {th }}$ position, the actuator extends from center position to one direction and changes the wheel direction. In this study the maximum angle that the wheel can turn for steering is found to be $25^{\circ}$ from normal position. Its speed can be varied by adjusting the setting of the throttle of the flow control valve. When the $6^{\text {th }}$ position of the four-way valve is in operation, the motor turns in the opposite direction.

\section{CONCLUSION}

In this article, a trencher machine, which can be used for diverse purposes such as to dig the ditch for laying pipes or cables, for installing drainage, irrigation, installing fencing, and in preparation for trench warfare, has been designed and analyzed. The cutting forces needed for trenching were calculated based on the FEE that was provided by Reece because it is clear and almost all the related work carried out previously by others is based on the same concept. Cutting force prediction for point-attack picks was based on the maximum value that is Goktan 
Type: Von Mises Stress

Unit: $\mathrm{MPa}$

6/13/2015, 12:53:16 AM

\begin{tabular}{|l}
29.53 \\
23.63 \\
17.72 \\
11.81 \\
5.91 \\
0 Min
\end{tabular}

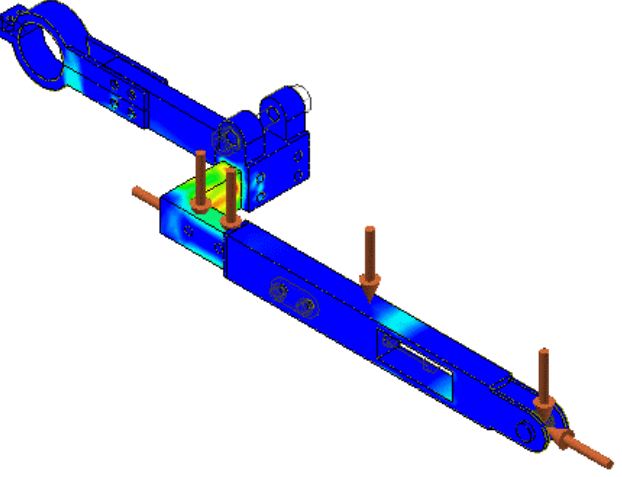

Fig. 9. Stress analysis report of boom

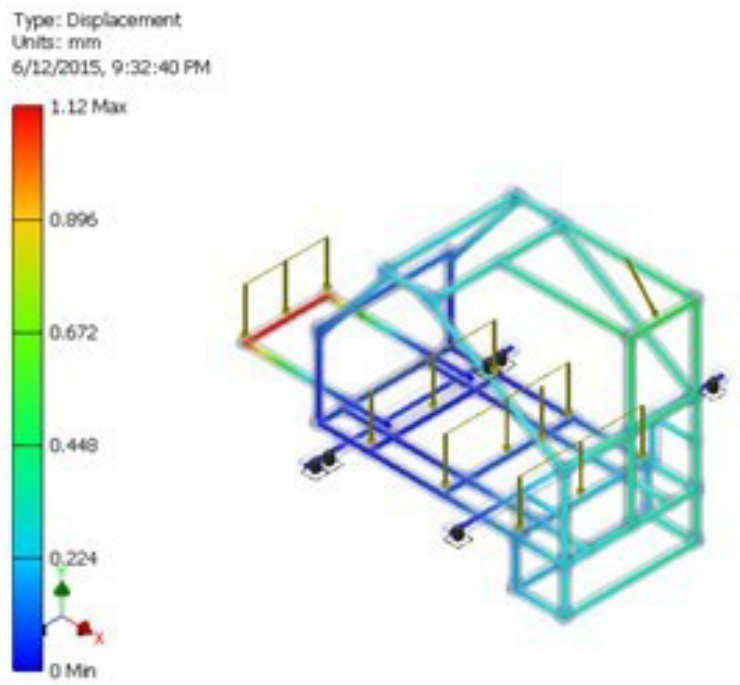

Fig. 10. Stress analysis report of frame formula and that is improvement on Evans' cutting theory. All machine elements of the trencher were carefully designed. The stress analysis plots were studied to check the maximum stress, safety factor and the displacements. Hydraulic circuit of the system was also designed to meet the design requirements and control the system. Based on the design and stress analysis, it is possible to conclude that this and similar light duty trencher helps to reduce labor intensive work and avoids the most tedious and handwork trenching with a reasonable cost and performance.

\section{REFERENCES}

1. Agustawijaya D.S., The uniaxial compressive strength of soft rock. Journal of Civil Engineering Science and Application, 9(1), 2007, 9-14.

2. Berhane, G. Engineering geological soil and rock characterization in the Mekelle Town, Northern Ethiopia: Implications to Engineering Practice. Momona Ethiop Journal of Science, 2(2), 2010, 64-86.

3. Patel, B. P. and Prajapati, J. M., Evaluation of resistive force using principle of soil mechanics for mini hydraulic backhoe excavator. International Journal of Machine Learning and Computing, 2 (4), 2012, 386 -391.

4. CWS website: Available at http://www.cwsindustries.com/\# (Last visit: 2018-01-15)

5. Deketh, H.J.R., Grima, M.A., Hergarden, I.M., Giezen, M. and Verhoef, P.N.W., Towards the prediction of rock excavation machine performance. Bulletin of Engineering Geolology and

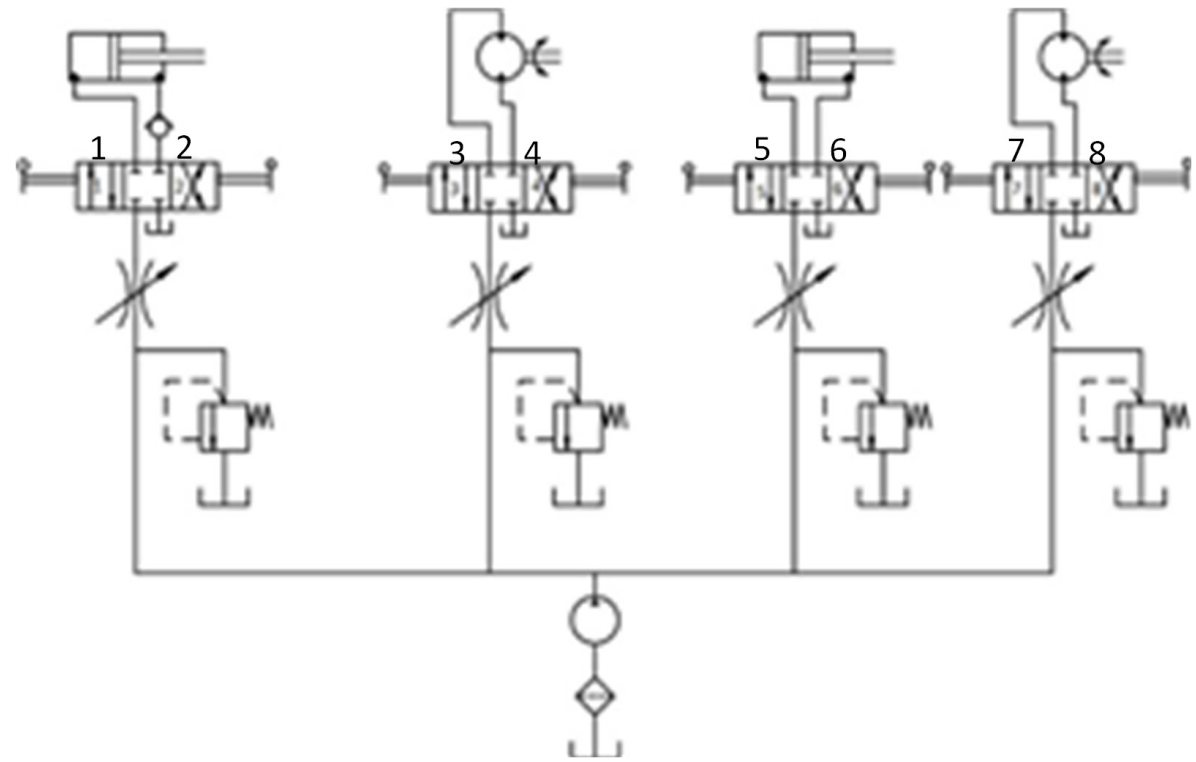

Fig. 11. Hydraulic circuit of the system 
the Environment, 57(1), 1998: 3-15. https://doi. org/10.1007/s100640050016.

6. den Hartog M.H., Babuška R., Deketh H.J.R., Grima, M.A., Verhoef, P.N.W. and Verbruggen, H.B., Knowledge-based fuzzy model for performance prediction of a rock-cutting trencher. International Journal of Approximate Reasoning, 16(1), 1997, 43-66.

7. Evans, I., A theory of the cutting force for point attack picks. International Journal of Mining and Geological Engineering, 2, 1984a, 63-71.

8. Evans, I. Basic mechanics of the point-attack pick. Colliery Guardian, 1984b, 189-193.

9. Goktan, R.M., A suggested improvement on Evans' cutting theory for conical bits, Proc. of the 4th International Symposium on Mine Mechanization and Automation, Brisbane, Queensland, Australia, 1, 1997, A4-57/A4-61.

10. Honda Web: http://engines.honda.com, Last visted: 2018-01-15.

11. Jibril, J., In-depth investigation into engineering characteristics of Jimma Soils, MSc thesis, Addis Ababa University, 2014.

12. Kang J., Parker F., Yoo, C., Soil-structure interaction and imperfect trench installations for deeply buried concrete pipes. Journal of Geotechnical and Geoenviromental Engineering, ASCE 133(3), 2007, 277-285.

13. Khurmi, R.S. and Gupta, J.K., A Textbook of Machine Design, 14th edition, Eurasia Publishing
House (PVT.) Ltd, Ram Nagar, New Delhi, 2005.

14. Perras, M.A. and Diederichs, M.S., A review of the tensile strength of rock: Concepts and testing. Geotechnical and Geological Engineering, 32(2), 2014, $525-546$.

15. McAffee, R.P., and Valsangkar, A.J., Field performance, centrifuge testing, and numerical modelling of an induced trench installation. Canadian Geotechnical Journal, 45(1), 2008, 85-101

16. Reece, R., The fundamental equation of Earthmoving machines. Proceeding of Institution of Mechanical Engineers, 179 Pt.3F, 1964, 16-22.

17. Scott, A.J. Flexible production systems and regional development: the rise of new industrial spaces in North America and western Europe. International Journal of Urban and Regional Research, 12(2), 1988, 171 -186, DOI: 10.1111/j.1468-2427.1988. tb00448.x

18. Storper, M. Industrialization and the regional question in the third world: Lessons of post imperialism; prospects of post-Fordism. International Journal of Urban and Regional Research, 14(3), 1990, 423444. DOI: 10.1111/j.1468-2427.1990.tb00149.x

19. Teferra, A. And Yohannes, S. Investigations on the expansive soils of Addis Ababa, Journal of EAEA, 7, 1986.

20. Zeng, X., Burnoski, L. Juan, H., and Wilkinson, A.A., Calculation of excavation force for ISRU on lunar surface, 45th AIAA Aerospace Sciences Meeting and Exhibit, 2007, https://doi.org/10.2514/6.2007-1474 